\title{
The study of metabolic improvement by nutritional intervention controlling endogenous GIP (Mini Egg study): a randomized, cross-over study
}

\author{
Naoki Sakane ${ }^{1 *}$ (D, Noriko Osaki ${ }^{2}$, Hideto Takase ${ }^{2}$, Junko Suzuki ${ }^{3}$, Chika Suzukamo $^{2}$, Shinsuke Nirengi ${ }^{1}$,
} Akiko Suganuma ${ }^{1}$ and Akira Shimotoyodome ${ }^{3}$

\begin{abstract}
Background: Given the major role of glucose-dependent insulinotropic polypeptide (GIP) in the regulation of adiposity, this study examined the effects induced by a diet based on the Japanese tradition (SMART WASHOKU) on the visceral fat area (VFA) and GIP secretions.

Methods: Overweight/obese men ( $n=21$; mean age, $41.0 \pm 9.0$ years; mean BMl, $25.2 \pm 2.0 \mathrm{~kg} / \mathrm{m}^{2}$ ) without diabetes were placed on either a SMART WASHOKU or control meal for 2 weeks, in a randomized, cross-over setup with a four-week washout period.

Results: For the meal tolerance test, blood samples were collected at 0, 30, 60, 120, 180, and 240 min post-meal, followed by measuring blood glucose, insulin, GIP, and glucagon-like peptide-1 (GLP-1) levels. Relative to a control meal, SMART WASHOKU meal yielded significantly lower plasma postprandial GIP concentrations (AUC: $700.0 \pm$ 208.0 vs. $1117.0 \pm 351.4 \mathrm{pmol} / \mathrm{L} \quad 4 \mathrm{~h}, P<0.05$ ); however, between meals, there was no significant difference in the levels of GLP-1, peptide YY, and ghrelin. Compared to the control meal, SMART WASHOKU intervention significantly reduced VFA and the levels of LDL-cholesterol, triglyceride, and HbA1c after the chronic meal intervention.
\end{abstract}

Conclusions: In conclusion, a SMART WASHOKU meal may decrease VFA and improve metabolic parameters in overweight/obese men, possibly via suppressing GIP secretion.

Keywords: Glucose-dependent insulinotropic polypeptide, Visceral fat, Traditional Japanese diet

\section{Background}

Glucose-dependent insulinotropic polypeptide (GIP) is an incretin hormone produced by $\mathrm{K}$ cells in the upper gastrointestinal tract [1]. The action of GIP is mediated by interactions with the GIP receptor that induces pancreatic beta-cells to release insulin [1]. In addition to pancreatic beta-cells, adipocytes express functional GIP receptors [2]. Animal studies have demonstrated that the regulation of adiposity is an important physiological function of GIP [3]. GIP induces glucose uptake, the

\footnotetext{
* Correspondence: nsakane@gf6.so-net.ne.jp

${ }^{1}$ Division of Preventive Medicine, Clinical Research Institute, National Hospital Organization Kyoto Medical Center, 1-1 Mukaihata-cho, Fukakusa, Fushimi-ku, Kyoto 612-8555, Japan

Full list of author information is available at the end of the article
}

activity of lipoprotein lipase, and induction of triglycerides by 3 T3-L1 adipocytes [4]. Deletion of GIP receptor counteracts diet-induced obesity in leptin-deficient mice, and conversely, administration of a GIP receptor antagonist was found to suppress weight gain in mice fed with a high-fat diet [5]. In a cross-sectional study, GIP secretion in early phase was found to be positively correlated with body mass index (BMI) in non-obese and obese patients with type 2 diabetes mellitus [6]. Common variants of GIP are known to be associated with the accumulation of visceral fat in humans $[7,8]$. Therefore, GIP is considered to play a critical role in the regulation of adiposity, especially visceral fat accumulation. Diet based on the Japanese tradition (A WASHOKU) is characterized by high consumption of fish and soybean

(C) The Author(s). 2019 Open Access This article is distributed under the terms of the Creative Commons Attribution 4.0 International License (http://creativecommons.org/licenses/by/4.0/), which permits unrestricted use, distribution, and 
products and low consumption of animal fat and meat [9]. Previously, the WASHOKU dietary pattern was shown to be associated with a decreased risk of cardiovascular mortality [10-13]. In a cross-sectional study, we found that a protein/fat ratio $\approx 1.0$, dietary fiber/carbohydrate ratio ( $\geqq 0.063)$, and $\mathrm{n}-3$ fatty acid/fat ratio ( $\geqq$ 0.054 ) were negatively associated with the accumulation of visceral fat [14]. Therefore, SMART WASHOKU was defined as Japanese dietary patterns with a protein/fat ratio $\approx 1.0$, dietary fiber/carbohydrate ratio $\geq 0.063$, and $\mathrm{n}-3$ fatty acid/fat ratio $\geq 0.04$. However, it remained unknown whether the SMART WASHOKU dietary intervention decreases visceral fat area (VFA); further, the mechanism associated with the reduced VFA have not been described. The $\mathrm{K}$-cell is considered to directly sense and respond to numerous nutrients in the intestine [15]. GIP secretions were suppressed by a vegetablerich mixed meal [16], although a high-fat diet enhanced GIP secretion [17]. Therefore, SMART WASHOKU might suppress GIP secretions. We hypothesized that a
SMART WASHOKU suppressed GIP secretions after meals and decreased VFA in overweight/obese males. The present study aimed to examine and compare the effects of SMART WASHOKU and modern Japanese meals on VFA and GIP secretions in overweight/obese men without diabetes.

\section{Methods}

\section{Trial design}

This study was a single-center, randomized, two-way crossover trial. Enrolled participants were overweight and obese men without diabetes. The study consisted of two intervention periods of 2 weeks separated by a washout period of 4 weeks (Fig. 1). Before the chronic meal intervention trial, a meal tolerance test was performed. The meal tolerance test was a randomized, twoway crossover trial with a washout period of 1 week. All subjects gave their informed consent for their participation in this study. The study was performed in accordance with the Declaration of Helsinki, approved by the

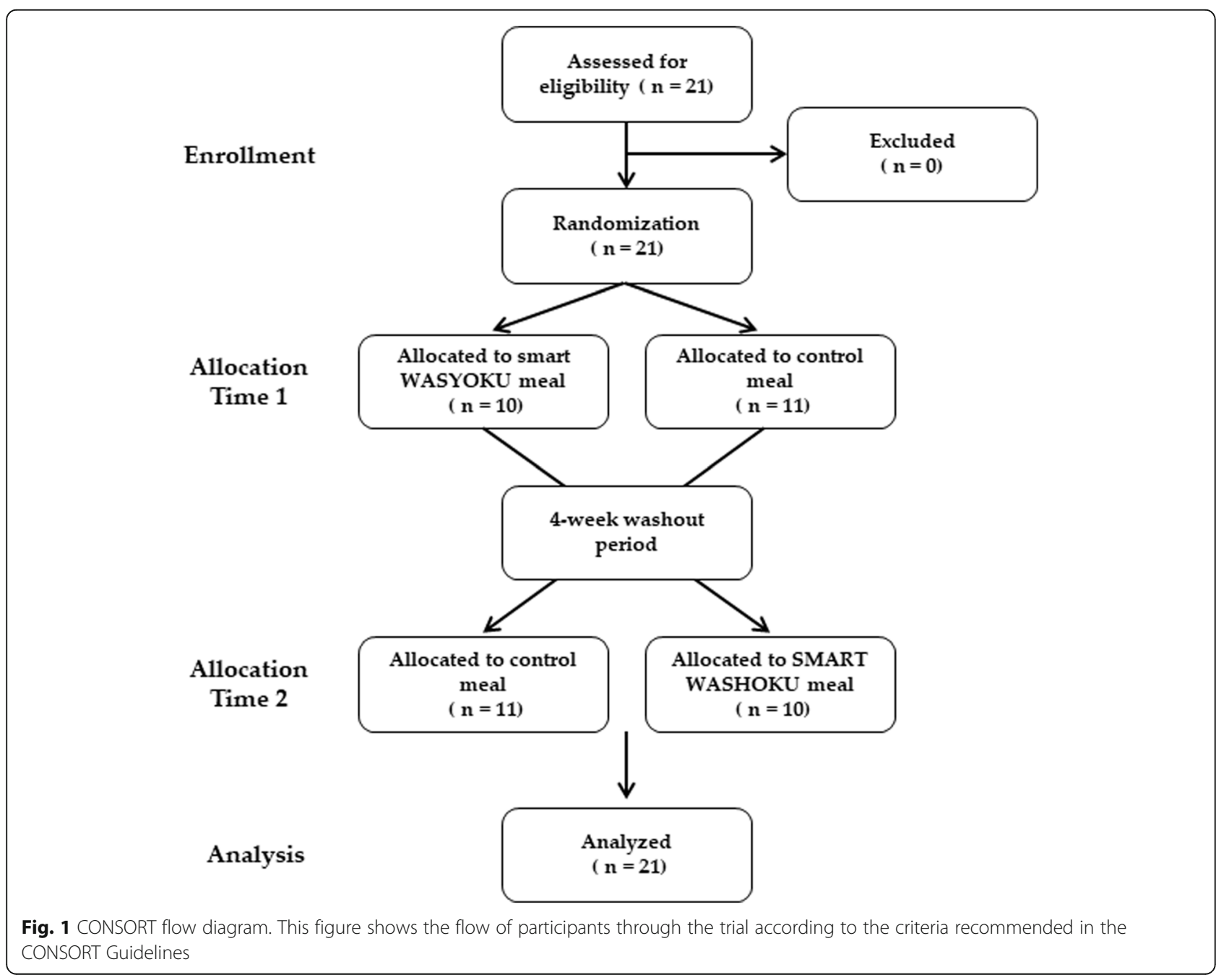


Institutional Review Board of Kyoto Medical Center (2014/12/25), and registered at University hospital Medical Information Network (UMIN) center (UMIN000016772).

\section{Participants and their selection}

Twenty-one individuals were recruited through poster advertisement and word of mouth across Kao Corporation. Following inclusion criteria were applied during the selection of candidates: (1) Japanese males between 20 and 59 years of age; (2) BMI $\geq 23 \mathrm{~kg} / \mathrm{m}^{2}$; (3) informed consent provided; (4) able to receive and cook experimental diet; (5) able to follow the instructions of the study team; and (6) participated in a meal tolerance test. The exclusion criteria were as follows: (1) plasma glucose value $\geq 126 \mathrm{mg} / \mathrm{dL}(7.0 \mathrm{mmol} / \mathrm{L})$, LDL-cholesterol value $\geq 180 \mathrm{mg} / \mathrm{dL} \quad(4.65 \mathrm{mmol} / \mathrm{L})$, triglyceride value $\geq 300 \mathrm{mg} / \mathrm{dL}$ (3.4 mmol/L), systolic blood pressure $\geq 160$ $\mathrm{mmHg}$; (2) weight change during the past year $\geq 3 \mathrm{~kg}$; (3) severe liver or renal dysfunctions; (4) shift and nightshift workers; (5) food allergy and suspected food allergy (self-reported); (6) an unbalanced diet (not able to eat fish and meat); (7) poor physical health such as rapid weight loss during the past 2 months; (8) plan to lose weight through vigorous exercise and resistance training; and (9) subjects determined ineligible (for some other reasons) by the investigator/project leader. Sex-based differences in the body fat distribution were observed $[18,19]$. Males are more likely to accumulate visceral fat than females. Therefore, we selected males only in this study. The cut-off for BMI was according to WHO standard criteria (underweight $<18.5$, normal 18.5-24.9, overweight $\geq 25-29.9$, and obese $\geq 30 \mathrm{~kg} / \mathrm{m}^{2}$ ) [20, 21]. Asian populations have a lower BMI associated with increased health risks compared with Caucasian populations [22]. Therefore, when this is taken into account, the cut-off of Asia-Pacific BMI was set as $\geq 23$ for overweight according to the Regional Office for the Western Pacific Region of the WHO [23, 24]. The study team adopted BMI of $\geq 23$ for potential health action points. This study did not include subjects who took diabetes medications.

\section{Meal tolerance test}

There were two different test meals, SMART WASHOKU and control. The test meals consisted of staple food, main dish, side dish, and soup. The energy compositions of the test meals are shown in Table 1.

During the day before each experimental day, subjects were encouraged to standardize their meal pattern and maintain regular eating habits. They were also instructed to avoid alcohol and excessive physical exercise during the day prior to the experimental day. On the experimental days, a test meal was served at 9:00 am, and the participants were required to finish their meal within $15 \mathrm{~min}$. Blood samples were collected at the following time points (minutes) before breakfast: 0, 30, 60, 120, 180, and 240.

\section{Intervention}

The study consisted of two periods of 2 weeks separated by a washout period of 4 weeks. SMART WASHOKU meals contained $2096 \mathrm{kcal}$ energy, $22.3 \%$ protein, $20.8 \%$ fat, dietary fiber/carbohydrate ratio $\geq 0.063$, and $n-3$ fatty acids/fat ratio $\geq 0.04$. Control meals contained $2096 \mathrm{kcal}$ energy, $13.7 \%$ protein, $37.5 \%$ fat, dietary fiber/carbohydrate ratio $\leq$ $0.063, \mathrm{n}-3$ fatty acids/fat ratio $\leq 0.04$. For 14 consecutive days, the participants were provided with commercially available meals (Table 2). We provided one meal selected from 5 meals for breakfast or lunch, and one meal selected from 5 meals for dinner by the rotation method. This is an

Table 1 Test meal composition of the Smart WASHOKU and control meals

\begin{tabular}{lll}
\hline Variables & Smart WASHOKU & Control meal \\
\hline Test meal & & Small portion steamed rice \\
Staple food & Steamed brown rice & Hashed beef \\
Main dish & Simmered mackerel with soy sauce & Boiled quail eggs, processed cheese \\
Side dish & Simmered daikon, fried fish balls and & shiitake mushrooms in soy sauce, \\
& simmered vegetables and beans, & - \\
Soup & Wakame seaweed soup & 636 \\
Total energy, kcal & 661 & 14.2 \\
Protein, \% & 20.5 & 34.4 \\
Fat, \% & 22.6 & 51.5 \\
Carbohydrate, \% & 56.9 & 0.412 \\
Protein/fat ratio & 0.905 & 0.027 \\
Fiber/carbohydrate ratio & 0.154 & 0.019 \\
n-3 fatty acid/lipid ratio & 0.090 & \\
\hline
\end{tabular}


Table 2 Example of experimental diet (Wednesday)

\begin{tabular}{|c|c|c|}
\hline Variables & Smart WASHOKU & Control meal \\
\hline \multicolumn{3}{|l|}{ Breakfast } \\
\hline Staple food & Steamed brown rice & Small portion steamed rice \\
\hline Main dish & Simmered mackerel with soy sauce & Hashed beef \\
\hline Side dish & $\begin{array}{l}\text { Simmered daikon, fried fish balls } \\
\text { and shiitake mushrooms in soy sauce, } \\
\text { simmered vegetables and beans, }\end{array}$ & Boiled quail eggs, processed cheese \\
\hline Soup & Wakame seaweed soup & - \\
\hline \multicolumn{3}{|l|}{ Lunch } \\
\hline Staple food & Steamed brown rice & Beef rice bowl \\
\hline Main dish & Japanese amberjack teriyaki & \\
\hline Side dish & $\begin{array}{l}\text { Simmered bamboo shoots, } \\
\text { butterbur and fried tofu in } \\
\text { soy sauce, Simmered beans }\end{array}$ & Pumpkin salada, boiled quail eggs \\
\hline Soup & Miso soup with welsh onion & - \\
\hline \multicolumn{3}{|l|}{ Dinner } \\
\hline Staple food & Steamed rice with mixed grains & Steamed rice \\
\hline Main dish & Salt-grilled salmon & Grilled pork with ginger \\
\hline Side dish & $\begin{array}{l}\text { Simmered vegetable and beans, } \\
\text { simmered pumpkin, simmered } \\
\text { hijiki seaweed, simmered daikon, } \\
\text { fried fish balls and shiitake } \\
\text { mushrooms in soy sauce }\end{array}$ & Potato salada,Processed cheese \\
\hline Soup & Miso soup with wakame seaweed & - \\
\hline
\end{tabular}

example of the experimental diet (Table 2). The test meals were provided at work sites on a working day. If participants requested meals at home, we delivered them to the homes. On holidays, we also delivered meals to their homes. Dietary adherence was based on daily nutrition logs. It was measured as the percentage of meals provided by the research group that participants ate.

\section{Outcomes}

The primary endpoint was the measurement of VFA by the abdominal bioelectrical impedance analysis (EW-FA90, Panasonic) [25]. VFA based on abdominal bioelectrical impedance analysis was correlated significantly with VFA determined by abdominal computed tomography $(r=0.88)$. The coefficient of variation of test-retest reliability was $0.89 \%$. Additional endpoints included determining weight, waist circumference, blood pressure, serum lipid, and GIP levels. We used a digital anthropometric scale (with an accuracy of $0.1 \mathrm{~kg}$ ) for the evaluation of body weight $(\mathrm{kg})$, and a stadiometer (with an accuracy of $0.1 \mathrm{~cm}$ ) to obtain height (m) of the participants. BMI was calculated by the ratio of weight $(\mathrm{kg})$ by the square of height $(\mathrm{m})$. Asian-specific BMI cut-offs were used to define overweight $(23.0$ to $<27.5 \mathrm{~kg}$ / $\left.\mathrm{m}^{2}\right)$ and obese $\left(\geq 27.5 \mathrm{~kg} / \mathrm{m}^{2}\right)[26]$.

The following variables were measured: Blood glucose (ACCU-CHEK AVIVA, Roche Diagnostics K.K.); serum insulin (enzyme linked immunoassay (ELISA) kits,
Mercodia Human Insulin ELISA Kit Mercodia AB); serum GIP (Human GIP (Total) ELISA Kit, EMD Millipore Co.); serum GLP-1 (Glucagon-Like Peptide-1(Active) ELISA Kit, EMD Millipore Co., Billerica, MA, USA); serum ghrelin (active) pancreatic polypeptide (MILLIPLEX MAP Human Metabolic Hormone Panel, EMD Millipore Co.); serum peptide (Human PYY (Total) ELISA Kit, EMD Millipore Co, Billerica, MA, USA). All assays had the inter-assay coefficient of variation $(\mathrm{CV})$ or intra-assay $\mathrm{CV}$ of $<10 \%$. HOMA-IR and HOMA- $\beta$ values were calculated to determine the insulin resistance and functional capacity of pancreatic beta cells, respectively [27]. Serum lipids, liver enzyme, and high sensitivity C-reactive protein (hs-CRP) were also measured. HbA1c levels were measured by the enzymatic method.

We measured the dietary status before dietary intervention and during the washout period. Dietary assessment was performed using a brief, validated selfadministered diet-history questionnaire [28].

\section{Sample size}

Sample sizes were estimated using the xsampsi command, which is Stata module to calculate the sample size for cross-over trials with continuous measures. It was calculated with the assumption that an improvement of $10 \mathrm{~cm}^{2}$ in VFA was clinically relevant. With an expected standard deviation (SD) within measurements of VFA of 
15 , alpha of 0.05 , and statistical power of 0.8 , we needed to study 18 participants in a cross-over design. However, considering the risk of drop-out, we choose to include 20 participants.

\section{Randomization}

The biostatistician supervisor, who was not aware of participants' conditions, randomly assigned patients (1:1) to either type A meal during period 1 followed by type $B$ meal during period 2 ( $\mathrm{AB}$ sequence); further, the reverse order of the meals (BA sequence) was also followed. Random allocation was performed with randomization software using stratification based on age group $(<40$ or $\geq 40$ years $)$ and BMI $\left(<25\right.$ or $\left.\geq 25 \mathrm{~kg} / \mathrm{m}^{2}\right)$.

\section{Blinding}

Study participants and investigators were not blinded to the dietary regimen. Analysts who performed final data analysis were blinded.

\section{Statistical analysis}

All the data were disclosed after the termination of the trial and analyzed by an independent investigator. Data are reported as mean (SD). The postprandial variations were integrated as the area under the curve (AUC). For each measurement, AUC was calculated according to the trapezoidal rule. Data for different time-points and treatments were analyzed by repeated-measures ANOVA, usingtwo factors (time; and time and treatment) as factors. The data were analyzed by analysis of variance using the pkcross command in Stata/IC 13.1 software. The $P$-value was calculated using the pkcross command in Stata/IC 13.1 software because of the cross-over design. When analyzing trial data with the pkcross command, if the treatment, carryover, and sequence variables are known, the omnibus test for separability of the treatment and carryover effects is calculated. A $p$ value of $<0.05$ was considered to be significantly different.

\section{Adverse event assessment}

Safety was assessed by the number of participants with adverse events (AEs). Using terms from the Medical Dictionary for Regulatory Activities, version 11.1, AE data were collected by systematic assessment of the participants who received one or more doses of intervention. AEs were not documented for the washout phase of the study.

\section{Results}

\section{Recruitment and participants' characteristics}

A total of 21 participants were included in the current study (Table 3), and all of them completed the study successfully (Fig. 1). Adherence with the diet regimen was $96 \pm 7 \%$ and $93 \pm 10 \%$ in a SMART WASHOKU and control meal, respectively. Baseline total energy, protein, fat, carbohydrate, and fiber intakes in participants were $2003 \pm 395 \mathrm{kcal}, 15.3 \pm 2.2 \%, 31.4 \pm 5.8 \%, 53.2 \pm 6.6 \%$, and $14.0 \pm 5.6 \mathrm{~g}$, respectively. The baseline protein/fat ratio, dietary fiber/carbohydrate ratio, and n-3 fatty acids/fat ratio were $0.50 \pm 0.10,0.058 \pm 0.020$, and $0.035 \pm 0.012$, respectively. These dietary patterns in participants were similar to control diets. The protein/fat ratio, dietary fiber/carbohydrate ratio, and n-3 fatty acid/fat ratio during the washout period were $0.55 \pm 0.13,0.059 \pm 0.017$, and $0.036 \pm 0.014$, respectively. These dietary patterns during the washout period in participants were similar to baseline dietary patterns. There was no difference in total calorie intake between a SMART WASHOKU and the control diet $(2097 \pm 42$ and $2110 \pm 20 \mathrm{kcal}$, respectively). The protein/fat ratio, dietary fiber/carbohydrate ratio, and n-3 fatty acid/fat ratio during the intervention of a SMART WASHOKU were $1.09 \pm 0.11,0.118 \pm$ 0.014 , and $0.125 \pm 0.019$, respectively. The protein/fat ratio, dietary fiber/carbohydrate ratio, and n-3 fatty acid/ fat ratio during the intervention of the control diet were $0.37 \pm 0.03,0.041 \pm 0.005$, and $0.023 \pm 0.003$, respectively.

\section{Meal tolerance test results}

Participants were placed on the meal plan described earlier in the Methods section, and blood samples were collected for assessing following several variables. Relative to a control meal, SMART WASHOKU meal had a significantly lower plasma postprandial GIP concentration (AUC: $1117.0 \pm 351.4$ vs. $700.0 \pm 208.0 \mathrm{pmol} / \mathrm{L} \quad 4 \mathrm{~h}$, $P<0.05)$; however, between meals, there was no

Table 3 Baseline characteristics of participants

\begin{tabular}{ll}
\hline Variables & Mean (SD) \\
\hline Age, years & $41.0(9.0)$ \\
Body weight, kg & $73.1(8.2)$ \\
BMl, kg/m² & $25.2(2.0)$ \\
Body fat, \% & $25.5(4.7)$ \\
VFA, cm ${ }^{2}$ & $107.7(30.6)$ \\
Waist circumference, cm & $90.1(4.7)$ \\
Hip circumference, cm & $99.4(4.4)$ \\
Fasting plasma glucose, mg/dL & $94.4(21.2)$ \\
HbA1c, \% & $5.5(0.5)$ \\
Triglyceride, mg/dL & $125.4(58.2)$ \\
LDL-cholesterol, mg/dL & $119.7(25.8)$ \\
HDL-cholesterol, mg/dL & $56.1(13.5)$ \\
Systolic blood pressure, mmHg & $131.5(13.1)$ \\
Diastolic blood pressure, mmHg & $87.5(11.4)$ \\
\hline
\end{tabular}

'Data are presented as mean (SD). BMI Body mass index, VFA Visceral fat area, HbA1c Hemoglobin A1c, LDL-cholesterol Low-density lipoprotein cholesterol, $H D L$-cholesterol High-density lipoprotein cholesterol 
significant difference in the levels of blood glucose, insulin, triglyceride, GLP-1, peptide YY (PYY), and ghrelin (Fig. 2).

\section{Outcomes}

Relative to control meal, a SMART WASHOKU intervention produced a modest but significant reduction of VFA in our participants $\left(-3.4 \pm 12.3\right.$ vs. $-13.0 \pm 9.3 \mathrm{~cm}^{2}$, $P<0.05)$. A carryover effect was not noted in this study ( $F$ value $=0.01, P=0.939)$. Compared with the control meal, SMART WASHOKU meal did not modify the concentrations of AST, ALT, $\gamma$-GT, and hs-CRP; however, we did observe a significantly reduced in the levels of LDL-cholesterol, triglyceride, and HbAlc (Table 4). There was no difference in total energy intake between the two intervention periods. However, the protein/fat ratio, fiber/carbohydrate ratio, and n-3 fatty acids in the SMART WASHOKU meal intervention period were significantly higher compared with the control meal intervention period (Table 5).

\section{Discussion}

In the present study, we found that a SMART WASHOKU meal decreases VFA and serum GIP secretions. The control diet was similar to the normal diet participants ate regularly. Normal diets before intervention and during the washout period were similar and consistent with a modern Japanese modern diet [29]. It has been shown that in obese individuals, insulin resistance reduces gastric inhibitory polypeptide receptor expression and GIP activity in subcutaneous adipose tissue but not in visceral adipose tissue $[30,31]$. Though GIP signaling is attenuated in the subcutaneous adipose tissue under conditions of insulin resistance, it is possible that GIP contributes to obesity by acting on visceral adipose tissue. Acute fat ingestion stimulates GIP secretion, while chronic high-fat diet loading enhances

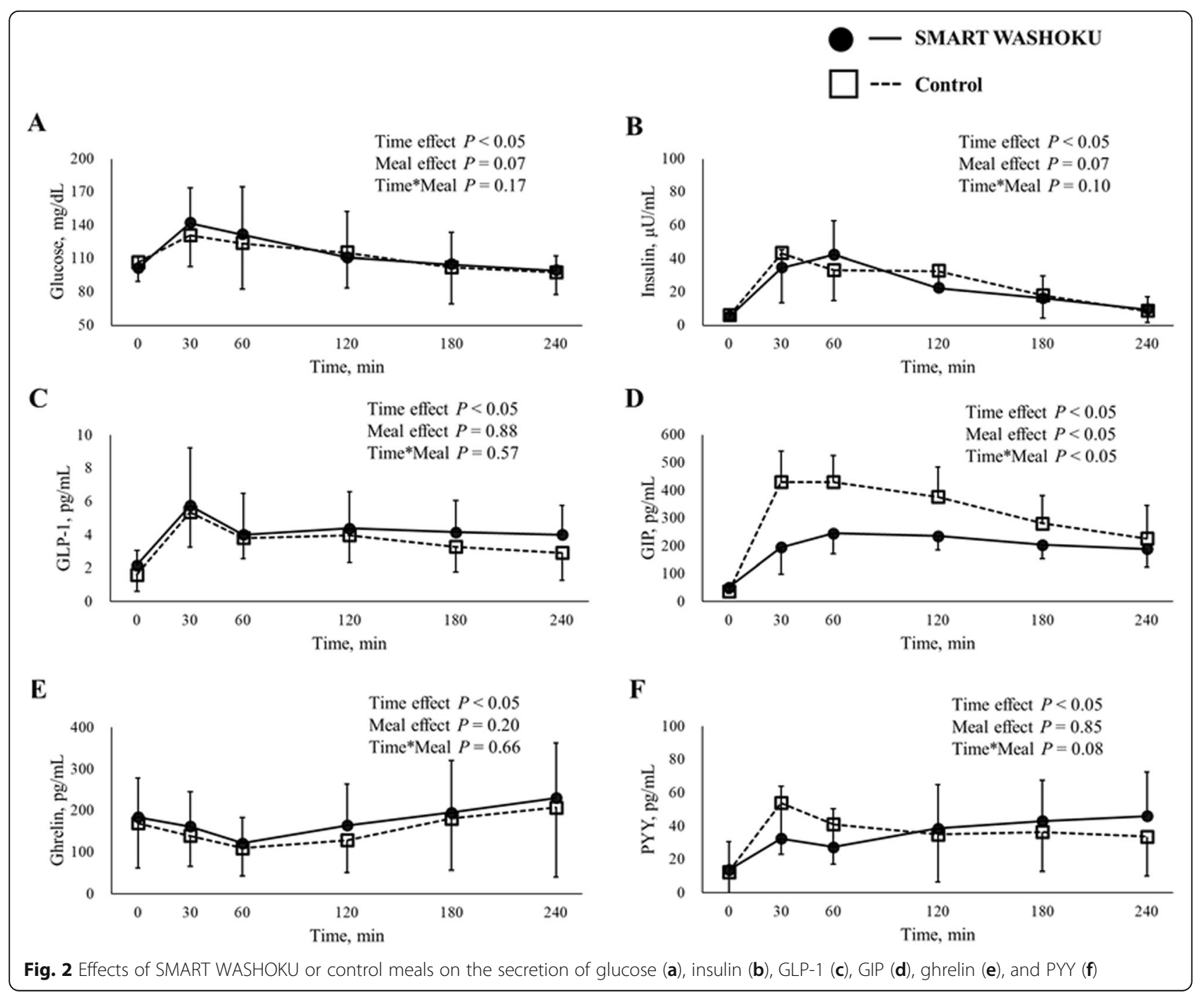


Table 4 Changes in metabolic parameters following SMART WASHOKU or control meals

\begin{tabular}{|c|c|c|c|}
\hline Variables & SMART WASHOKU & Control & $P$ value \\
\hline Body weight, kg & $-0.97(1.04)$ & $-0.69(0.82)$ & 0.297 \\
\hline Body mass index, $\mathrm{kg} / \mathrm{m}^{2}$ & $-0.33(0.36)$ & $-0.23(0.28)$ & 0.332 \\
\hline Body fat, $\%$ & $0.05(1.30)$ & $-0.08(1.61)$ & 0.777 \\
\hline VFA, $\mathrm{cm}^{2}$ & $-13.0(9.3)$ & $-3.4(12.3)$ & 0.005 \\
\hline Waist circumference, cm & $-1.85(1.7)$ & $-0.86(1.6)$ & 0.102 \\
\hline Hip circumference, cm & $-0.17(0.9)$ & $-0.19(0.9)$ & 0.893 \\
\hline Systolic blood pressure, mmHg & $-2.3(7.7)$ & $-1.6(8.5)$ & 0.675 \\
\hline Diastolic blood pressure, $\mathrm{mmHg}$ & $-2.0(5.1)$ & $-0.6(6.1)$ & 0.352 \\
\hline Fasting plasma glucose, mg/dL & $-1.7(8.4)$ & $-0.2(5.2)$ & 0.503 \\
\hline $\mathrm{HbA} 1 \mathrm{c}, \%$ & $-0.15(0.12)$ & $-0.08(0.08)$ & 0.022 \\
\hline Fasting serum insulin, IU & $-0.6(1.7)$ & $0.1(1.9)$ & 0.248 \\
\hline HOMA-IR & $-0.2(0.6)$ & $0.0(0.4)$ & 0.054 \\
\hline HOMA- $\beta$ & $-3.6(28.3)$ & $-15.9(64.9)$ & 0.476 \\
\hline Triglyceride, mg/dL & $-47.7(57.4)$ & $5.9(59.4)$ & 0.016 \\
\hline LDL-cholesterol, mg/dL & $-25.1(12.2)$ & $0.95(16.6)$ & $<0.001$ \\
\hline HDL-cholesterol, mg/dL & $-8.0(4.7)$ & $-3.1(6.4)$ & 0.008 \\
\hline AST, IU/L & $0.2(3.8)$ & $-1.1(4.1)$ & 0.304 \\
\hline ALT, IU/L & $-2.4(8.9)$ & $-0.2(7.9)$ & 0.370 \\
\hline$\gamma-G T, I U / L$ & $-8.9(15.1)$ & $-0.9(8.8)$ & 0.058 \\
\hline hs-CRP & $0.02(0.08)$ & $-0.04(0.14)$ & 0.104 \\
\hline
\end{tabular}

${ }^{1}$ Data are presented as mean (SD). AST Aspartate transaminase, ALT Alanine transaminase, $\gamma$-GT $\gamma$-glutamyltranspeptidase, $H s$-CRP High-sensitivity C-reactive protein

GIP secretion and induces obesity in mice [17]. Relative to the traditional diet, Japanese modern diet produced higher levels of serum GIP [32]. The Japanese traditional diet is characterized by high consumption of fish and soybean products and low consumption of animal fat and meat [9]. Thus, postprandial GIP secretion is stimulated by macronutrients, especially diet enriched with saturated fat [33-36]. In addition, fish oil, which is rich in polyunsaturated fatty acids, suppresses the postprandial GIP response more effectively than cocoa butter and olive oil [37]. However, it has been shown that in healthy young and lean females,

Table 5 Nutrient intake of participants between the SMART WASHOKU and control meal intervention periods

\begin{tabular}{llll}
\hline Variables & SMART WASHOKU & Control meal & $P$ value \\
\hline Total energy, kcal & $2097(41)$ & $2110(19)$ & 0.311 \\
Protein, \% & $22.7(0.7)$ & $13.7(0.6)$ & $<0.001$ \\
Fat, \% & $21.0(1.5)$ & $37.5(1.7)$ & $<0.001$ \\
Carbohydrate, \% & $56.3(1.4)$ & $48.8(1.4)$ & $<0.001$ \\
Protein/fat ratio & $1.089(0.105)$ & $0.366(0.030)$ & $<0.001$ \\
Fiber/carbohydrate ratio & $0.118(0.014)$ & $0.041(0.005)$ & $<0.001$ \\
n-3 fatty acid/lipid ratio & $0.125(0.019)$ & $0.023(0.002)$ & $<0.001$ \\
\hline Mean (standard deviation) & & &
\end{tabular}

Mean (standard deviation) there was no difference in postprandial GIP secretion induced by coconut fat (a source for saturated fatty acids), linseed oil, and a mixture of linseed and cod liver oil [38]. In the present study, we found that a SMART WASHOKU meal decreases serum GIP secretions during a meal tolerance test and VFA during a 2-week dietary intervention. However, these findings did not reflect the direct relationship of GIP influencing VFA. Careful attention should be paid to the interpretation of these findings. Further examination including elucidation of the mechanism is required to investigate these issues in mice and humans.

In the current study, SMART WASHOKU meal improved LDL-cholesterol levels, a result that was not observed with the control meal. This is consistent with the recent finding that GIPR antagonist inhibits the uptake of lipids and improves lipid metabolism, resulting in suppression of body-weight gain in mice [39]. Additionally, SMART WASHOKU meal resulted in an improvement in HbA1c levels and HOMA-IR. Despite a reduction in VFA and insulin resistance, the WASHOKU meal-induced mechanisms responsible for improving metabolic parameters remain unknown, warranting further investigation in this direction. 
There are several reports on relationships between a low-fat diet and visceral fat reduction. Veum et al. reported no difference in the visceral fat mass after very high-fat (73\% of energy fat and $10 \%$ of energy carbohydrate) and low-fat (30\% of energy fat and 53\% of energy carbohydrate) isocaloric diets in obese males [40]. This study was the first to show the relationships between isocaloric diets (SMART WASHOKU and modern Japanese diet) and VFA in overweight/ obese males. We assigned 5 test meals for breakfast and lunch, and 5 test meals for dinner. Therefore, we suggest that it was not difficult for obese people to select foods making up SMART WASHOKU in a real-world way. In this study, decreased $\gamma$-GT due to dietary intervention was observed. Increases in $\gamma$-GT are associated with hepatic steatosis [41]. Hepatic steatosis can occur because of nonalcoholic fatty liver disease, alcoholism, chemotherapy, and metabolic, toxic, and infectious causes [42]. However, we did not conduct abdominal sonography or magnetic resonance imaging. Our dietary intervention might improve hepatic steatosis. Further examination including abdominal ultrasonography is needed to examine fat storage excess.

While the strengths of this study included a welldesigned cross-over randomized trial and high-level adherence to the dietary regimen, there were also several limitations, such as the small sample size, short experimental period, and males only. Therefore, this might have limited generalizability. At least $>3$-week or $\geq 12$-week dietary intervention is desirable $[43,44]$, but long-term intervention was difficult because of the cost and burden involved. However, the two-week dietary intervention resulted in decreases in the body weight and body fat mass $[45,46]$. Further examination including long-term follow-up and females is required to confirm these findings. Also, dietary adherence and intake were self-reported. Dietary adherence was self-reported. Accurate adherence may be realized by taking photos of participant's meals. Typically, high adherence to a diet was defined as $\geq 80 \%$ [47]. Adherence to the dietary regimen was $96 \pm 7$ and $93 \pm 10 \%$ for SMART WASHOKU and control meals, respectively. Taking into account the shortterm intervention, we think that the rate of adherence to the dietary regimen was high. In our study, we believe that the visceral fat reduction was low because of the short duration of the experiment. However, consistent with the previous report [48], we observed that a modest reduction in VFA $\left(-14\right.$ to $\left.0 \mathrm{~cm}^{2}\right)$ was associated with a decrease in the number of metabolic risk factors. We adopted an Asian-specific cut-off of BMI $\geq 23$ as overweight; therefore, the results are less generalizable for Caucasian populations.

\section{Conclusion}

Based on our findings, we conclude that in overweight/ obese men, a SMART WASHOKU meal would be helpful in decreasing VFA and improving metabolic parameters, possibly via suppressing GIP secretion. We did not measure the gut flora. Further examination including gut flora is required to investigate the association with SMART WASHOKU and gut flora in the future.

\section{Abbreviations \\ AE: Adverse events; ALT: Alanine aminotransferase; AST: Aspartate aminotransferase; AUC: Area under the curve; BMI: Body mass index; CV: Coefficient of variation; ELISA: Enzyme linked immunoassay; GIP: Glucose- dependent insulinotropic peptide; GLP-1: Glucagon-like peptide 1; \\ HbA1c: Hemoglobin A1c; HDL: High density lipoprotein; HOMA: Homeostasis model assessment; hs-CRP: high sensitivity C-reactive protein; LDL: Low density lipoprotein; PYY: Peptide YY; SD: Standard deviation; VFA: Visceral fat area; $\gamma$-GT: $\gamma$-glutamyltranspeptidase}

\section{Acknowledgements \\ We would like to thank all participants for their contributions to this study.}

\section{Authors' contributions}

NS was involved in all aspects of the study. NS, NO, and AS designed the study, and prepared the protocol. NO, HT, JS, CS, and AS performed the experiments. NS was involved in drafting the manuscript. NS, SN, and SA participated in statistical analysis. All the authors have read and approved the final version of the manuscript.

\section{Funding}

This work was financed by Kao Corporation, JSPS KAKENHI Grant Number 18 K01988 and SIP (Project ID 14533567), Technologies for creating nextgeneration agriculture, forestry and fisheries (Bio-oriented Technology Research Advancement Institution, NARO).

\section{Availability of data and materials}

The datasets used and/or analysed during the current study are available from the corresponding author on reasonable request.

\section{Ethics approval and consent to participate}

The study was performed in accordance with the Declaration of Helsinki, approved by the Institutional Review Board of Kyoto Medical Center (2014/ 12/25), and registered at University hospital Medical Information Network (UMIN) center (UMIN000016772)

\section{Consent for publication}

Not applicable.

\section{Competing interests}

$\mathrm{NO}, \mathrm{HT}, \mathrm{JS}, \mathrm{CS}$, and AS are employed by Kao corporation. Although NO, HT, $J S, C S$, and AS were involved in the design of the study and the collection of data, they did not involve in analyses or interpretation data.

\section{Author details}

${ }^{1}$ Division of Preventive Medicine, Clinical Research Institute, National Hospital Organization Kyoto Medical Center, 1-1 Mukaihata-cho, Fukakusa, Fushimi-ku, Kyoto 612-8555, Japan. ${ }^{2}$ Biological ScienceResearch, Kao Corporation, 2-1-3 Bunka, Sumida, Tokyo 131-8501, Japan. ${ }^{3}$ Biological Science Research, Kao Corporation, 2606 Akabane, Ichikai-machi, Haga-gun, Tochigi 321-3497, Japan.

Received: 2 April 2019 Accepted: 13 August 2019

Published online: 02 September 2019

\section{References}

1. Yabe D, Seino Y. Incretin actions beyond the pancreas: lessons from knockout mice. Curr Opin Pharmacol. 2013;13:946-53. 
2. Mclntosh $\mathrm{CH}$, Widenmaier S, Kim SJ. Glucose-dependent insulinotropic polypeptide signaling in pancreatic $\beta$-cells and adipocytes. J Diabetes Investig. 2012;3:96-106

3. Shimazu-Kuwahara S, Harada N, Yamane S, Joo E, Sankoda A, Kieffer TJ, Inagaki N. Attenuated secretion of glucose-dependent insulinotropic polypeptide (GIP) does not alleviate hyperphagic obesity and insulin resistance in Ob/Ob mice. Mol Metab. 2017;6:288-94.

4. Kim SJ, Nian C, Mclntosh CH. GIP increases human adipocyte LPL expression through CREB and TORC2-mediated trans-activation of the LPL gene. J Lipid Res. 2010:51:3145-57.

5. Lamont BJ, Drucker DJ. Differential antidiabetic efficacy of incretin agonists versus DPP-4 inhibition in high fat fed mice. Diabetes. 2008;57:190-8.

6. Kamoi K, Shinozaki Y, Furukawa K, Sasaki H. Potential correlation between plasma total GIP levels and body mass index in Japanese patients with types 1 or 2 diabetes mellitus. Endocr J. 2012;59:353-63.

7. Wang T, Ma X, Tang T, Higuchi K, Peng D, Zhang R, Chen M, Yan J, Wang S, Yan D, He Z, Jiang F, Bao Y, Jia W, Ishida K, Hu C. The effect of glucosedependent insulinotropic polypeptide (GIP) variants on visceral fat accumulation in Han Chinese populations. Nutr Diabetes. 2017:7:e278.

8. Nakayama K, Watanabe K, Boonvisut S, Makishima S, Miyashita H, Iwamoto S. Common variants of GIP are associated with visceral fat accumulation in Japanese adults. Am J Physiol Gastrointest Liver Physiol. 2014;307:G1108-14.

9. Gabriel AS, Ninomiya K, Uneyama $H$. The role of the Japanese traditional diet in healthy and sustainable dietary patterns around the world. Nutrients. 2018;10.

10. Shimazu T, Kuriyama S, Hozawa A, Ohmori K, Sato Y, Nakaya N, Nishino Y, Tsubono Y, Tsuji I. Dietary patterns and cardiovascular disease mortality in Japan: a prospective cohort study. Int J Epidemiol. 2007;36:600-9.

11. Nakamura Y, Ueshima H, Okamura T, Kadowaki T, Hayakawa T, Kita Y, Abbott RD, Okayama A. National Integrated Project for Prospective Observation of Non-Communicable Diseases and its Trends in the Aged, 1980 Research Group. A Japanese diet and 19-year mortality: national integrated project for prospective observation of non-communicable diseases and its trends in the aged, 1980. Br J Nutr. 2009;101:1696-705.

12. Okada E, Nakamura K, Ukawa S, Wakai K, Date C, Iso H, Tamakoshi A. The Japanese food score and risk of all-cause, CVD and cancer mortality: the Japan collaborative cohort study. Br J Nutr. 2018;120:1-8.

13. Nanri A, Mizoue T, Shimazu T, Ishihara J, Takachi R, Noda M, Iso H, Sasazuki S, Sawada N, Tsugane S. Japan Public Health Center-Based Prospective Study Group. Dietary patterns and all-cause, cancer, and cardiovascular disease mortality in Japanese men and women: The Japan public health center-based prospective study. PLoS One. 2017;12:e0174848.

14. Takase H, Sakane N, Morimoto T, Uchida T, Mori K, Katashima M, Katsuragi Y Development of a dietary factor assessment tool for evaluating associations between visceral fat accumulation and major nutrients in Japanese adults. J Obes. 2019;10:9497861.

15. Ugleholdt R. Glucose-dependent Insulinotropic polypeptide (GIP): from prohormone to actions in endocrine pancreas and adipose tissue. Dan Med Bull. 2011;58:B4368.

16. Bligh HF, Godsland IF, Frost G, Hunter KJ, Murray P, MacAulay K, Hyliands D, Talbot DC, Casey J, Mulder TP, Berry MJ. Plant-rich mixed meals based on Palaeolithic diet principles have a dramatic impact on incretin, peptide YY and satiety response, but show little effect on glucose and insulin homeostasis: an acute-effects randomised study. Br J Nutr. 2015;113:574-84.

17. Yamane S, Harada N, Inagaki N. Mechanisms of fat-induced gastric inhibitory polypeptide/glucose-dependent insulinotropic polypeptide secretion from K cells. J Diabetes Investig. 2016;7(Suppl 1):20-6.

18. Tanaka S, Horimai C, Katsukawa F. Ethnic differences in abdominal visceral fat accumulation between Japanese, African-Americans, and Caucasians: a meta-analysis. Acta Diabetol. 2003;40(Suppl 1):S302-4.

19. Tchernof A, Després JP. Pathophysiology of human visceral obesity: an update. Physiol Rev. 2013;93:359-404.

20. Yoon JL, Cho JJ, Park KM, Noh HM, Park YS. Diagnostic performance of body mass index using the Western Pacific regional Office of World Health Organization reference standards for body fat percentage. J Korean Med Sci. 2015;30:162-6.

21. Wen CP, David Cheng TY, Tsai SP, Chan HT, Hsu HL, Hsu CC, Eriksen MP. Are Asians at greater mortality risks for being overweight than Caucasians? Redefining obesity for Asians. Public Health Nutr. 2009;12:497-506.

22. Kagawa M, Kerr D, Binns C. Ethnic differences in the BMI-\%BF relationships between young Japanese and Australian-Caucasian males living in Australia using dual-energy X-ray absorptiometry. Asia Pac J Public Health. 2003; 15(Suppl):S27-32.

23. Shiwaku K, Anuurad E, Enkhmaa B, Nogi A, Kitajima K, Shimono K, Yamane Y, Oyunsuren T. Overweight Japanese with body mass indexes of 23.0-24.9 have higher risks for obesity-associated disorders: a comparison of Japanese and Mongolians. Int J Obes Relat Metab Disord. 2004;28:152-8.

24. Somprasit C, Tanprasertkul C, Rattanasiri T, Saksiriwutth P, Wongkum J, Kovavisarach E, Jongfueangparinya K, Panichakul P, Wuthiwong J. High prepregnancy body mass index and the risk of poor obstetrics outcomes among Asian women using BMI criteria for Asians by World Health Organization Western Pacific region (WPRO): a large cohort study. J Med Assoc Thail. 2015;98(Suppl 2):S101-7.

25. Ryo M, Maeda K, Onda T, Katashima M, Okumiya A, Nishida M, Yamaguchi T, Funahashi T, Matsuzawa Y, Nakamura T, Shimomura I. A new simple method for the measurement of visceral fat accumulation by bioelectrical impedance. Diabetes Care. 2005;28:451-3.

26. WHO Expert Consultation. Appropriate body-mass index for Asian populations and its implications for policy and intervention strategies. Lancet. 2004;363:157-63.

27. Levy JC, Matthews DR, Hermans MP. Correct homeostasis model assessment (HOMA) evaluation uses the computer program. Diabetes Care. 1998;21: 2191-2.

28. Kobayashi S, Murakami K, Sasaki S, Okubo H, Hirota N, Notsu A, Fukui M, Date $C$. Comparison of relative validity of food group intakes estimated by comprehensive and brief-type self-administered diet history questionnaires against 16 d dietary records in Japanese adults. Public Health Nutr. 2011;14: 1200-11.

29. Sugawara S, Kushida M, Iwagaki Y, Asano M, Yamamoto K, Tomata Y, Tsuji I, Tsuduki T. The 1975 type Japanese diet improves lipid metabolic parameters in younger adults: a randomized controlled trial. J Oleo Sci. 2018:67:599-607.

30. Ceperuelo-Mallafré V, Duran X, Pachón G, Roche K, Garrido-Sánchez L, Vilarrasa N, Tinahones FJ, Vicente V, Pujol J, Vendrell J, Fernández-Veledo S. Disruption of GIP/GIPR axis in human adipose tissue is linked to obesity and insulin resistance. J Clin Endocrinol Metab. 2014;99:E908-19.

31. Rudovich N, Kaiser S, Engeli S, Osterhoff M, Gögebakan O, Bluher M, Pfeiffer AF. GIP receptor mRNA expression in different fat tissue depots in postmenopausal non-diabetic women. Regul Pept. 2007;142:138-45.

32. Osaki N, Suzukamo C, Onizawa K, Hase T, Shimotoyodome A. Increased plasma levels of glucose-dependent insulinotropic polypeptide are associated with decreased postprandial energy expenditure after modern Japanese meals. Eur J Nutr. 2017;56:1693-705.

33. Thomsen C, Rasmussen O, Lousen T, Holst JJ, Fenselau S, Schrezenmeir J, Hermansen K. Differential effects of saturated and monounsaturated fatty acids on postprandial lipemia and incretin responses in healthy subjects. Am J Clin Nutr. 1999;69:1135-43.

34. Vilsbø\|l T, Krarup T, Sonne J, Madsbad S, Vølund A, Juul AG, Holst JJ. Incretin secretion in relation to meal size and body weight in healthy subjects and people with type 1 and type 2 diabetes mellitus. J Clin Endocrinol Metab. 2003;88:2706-13.

35. Itoh K, Moriguchi R, Yamada Y, Fujita M, Yamato T, Oumi M, Holst JJ, Seino $Y$. High saturated fatty acid intake induces insulin secretion by elevating gastric inhibitory polypeptide levels in healthy individuals. Nutr Res. 2014;34: 653-60.

36. Ohlsson B, Höglund P, Roth B, Darwiche G. Modification of a traditional breakfast leads to increased satiety along with attenuated plasma increments of glucose, C-peptide, insulin, and glucose-dependent insulinotropic polypeptide in humans. Nutr Res. 2016;36:359-68.

37. Lardinois CK, Starich GH, Mazzaferri EL. The postprandial response of gastric inhibitory polypeptide to various dietary fats in man. J Am Coll Nutr. 1988;7:241-7.

38. Narverud I, Myhrstad MC, Herzig KH, Karhu T, Dahl TB, Halvorsen B, Ulven SM, Holven KB. Lack of effects of a single high-fat meal enriched with vegetable $n-3$ or a combination of vegetable and marine $n-3$ fatty acids on intestinal peptide release and Adipokines in healthy female subjects. Front Nutr. 2016;3:38.

39. Nakamura $T$, Tanimoto $H$, Mizuno $Y$, Okamoto $M$, Takeuchi $M$, Tsubamoto $Y$, Noda H. Gastric inhibitory polypeptide receptor antagonist, SKL-14959, suppressed body weight gain on diet-induced obesity mice. Obes Sci Pract. 2018;4:194-203.

40. Veum VL, Laupsa-Borge J, Eng $\varnothing$, Rostrup E, Larsen $T H$, Nordrehaug JE, Nygård OK, Sagen JV, Gudbrandsen OA, Dankel SN, Mellgren G. Visceral 
adiposity and metabolic syndrome after very high-fat and low-fat isocaloric diets: a randomized controlled trial. Am J Clin Nutr. 2017;105:85-99.

41. Hossain IA, Rahman Shah MM, Rahman MK, Ali L. Gamma glutamyl transferase is an independent determinant for the association of insulin resistance with nonalcoholic fatty liver disease in Bangladeshi adults: association of GGT and HOMA-IR with NAFLD. Diabetes Metab Syndr. 2016; 10:525-9.

42. Idilman IS, Ozdeniz I, Karcaaltincaba M. Hepatic steatosis: etiology, patterns, and quantification. Semin Ultrasound CT MR. 2016;37:501-10.

43. Borgeraas H, Johnson LK, Skattebu J, Hertel JK, Hjelmesaeth J. Effects of probiotics on body weight, body mass index, fat mass and fat percentage in subjects with overweight or obesity: a systematic review and metaanalysis of randomized controlled trials. Obes Rev. 2018;19:219-32.

44. Mumme K, Stonehouse W. Effects of medium-chain triglycerides on weight loss and body composition: a meta-analysis of randomized controlled trials. J Acad Nutr Diet. 2015;115:249-63.

45. Kovacs EM, Westerterp-Plantenga MS, Saris WH. The effects of 2-week ingestion of (--)-hydroxycitrate and (--)-hydroxycitrate combined with medium-chain triglycerides on satiety, fat oxidation, energy expenditure and body weight. Int J Obes Relat Metab Disord. 2001;25:1087-94.

46. Choi HR, Kim J, Lim H, Park YK. Two-Week exclusive supplementation of modified Ketogenic Nutrition Drink Reserves Lean Body Mass and Improves Blood Lipid Profile in Obese Adults: A Randomized Clinical Trial. Nutrients. 2018;10.

47. Nagpal TS, Prapavessis H, Campbell C, Mottola MF. Measuring adherence to a nutrition and exercise lifestyle intervention: is program adherence related to excessive gestational weight gain? Behav Anal Pract. 2017;10:347-54.

48. Okauchi Y, Nishizawa H, Funahashi T, Ogawa T, Noguchi M, Ryo M, Kihara S, Iwahashi H, Yamagata K, Nakamura T, Shimomura I, Matsuzawa Y. Reduction of visceral fat is associated with decrease in the number of metabolic risk factors in Japanese men. Diabetes Care. 2007;30:2392-4.

\section{Publisher's Note}

Springer Nature remains neutral with regard to jurisdictional claims in published maps and institutional affiliations.

Ready to submit your research? Choose BMC and benefit from:

- fast, convenient online submission

- thorough peer review by experienced researchers in your field

- rapid publication on acceptance

- support for research data, including large and complex data types

- gold Open Access which fosters wider collaboration and increased citations

- maximum visibility for your research: over $100 \mathrm{M}$ website views per year

At $\mathrm{BMC}$, research is always in progress.

Learn more biomedcentral.com/submissions 